\section{BIBLIOGRAFÍA}

1. Nitzan O, Elias M, Chazan B, et al. Urinary tract infections in patients with type 2 diabetes mellitus: review of prevalence, diagnosis, and management. Diabetes, Metab Syndr Obes:Targets and Therapy 2015; 26(8): 129-36.

2. Fünfstück $R$, Nicolle $L E$, Hanefeld $M$, et al. Urinary tract infection in patients with diabetes mellitus. Clin Nephrol 2012;77(1):40-48.

3. Urinary tract infection (lower): antimicrobial prescribing guidance. NICE guideline. Draft for consultation, May 2018. Disponible en: https://www.nice.org.uk/guidance/indevelopment/ gid-apg10004.

4. Geerlings SE. Urinary tract infections in patients with diabetes mellitus: epidemiology, pathogenesis and treatment. Int J Antimicrob Agents 2008; 31(Suppl 1):S54-7.
5. Grabe M, Bartoleti R, Bjerklund Johansen TE, et al. Guidelines on Urological Infections. European Association of Urology 2015. Disponible en: https://uroweb.org/wp-content/ uploads/19-Urological-infections_LR2.pdf.

6. Munar MY, Singh $\mathrm{H}$. Drug dosing adjustments in patients with chronic kidney disease. Am Fam Physician 2007; 75(10):1487-96.

7. Gupta K, Hooton TM, Naber KG, et al. Infectious Diseases Society of America; European Society for Microbiology and Infectious Diseases. International clinical practice guidelines for the treatment of acute uncomplicated cystitis and pyelonephritis in women: a 2010 update by the Infectious Diseases Society of America and the European Society for Microbiology and Infectious Diseases. Clin Infect Dis 2011; 52(5):e103-e120.

8. Consenso Argentino Intersociedades para el Manejo de la Infección del Tracto Urinario. Rev Panam Infectol 2007; 9(3):57-69.

\title{
TRATAMIENTO NO FARMACOLÓGICO DE LA INFECCIÓN URINARIA
}

\section{NON-PHARMACOLOGICAL TREATMENT OF URINARY INFECTION}

\author{
Estrella Menéndez ${ }^{1}$
}

\section{RESUMEN}

En varios estudios in vitro se observó que el jugo y cóctel de cranberries tenían efectos inhibitorios sobre la adherencia bacteriana pero sin poder bactericida, por lo tanto se propuso su uso para prevención de la infección urinaria (IU). Estudios clínicos sobre la eficacia del jugo de cranberries han sido limitados y no han demostrado disminución en la aparición de la infección del tracto urinario (ITU), desaconsejando su uso prolongado y aparición de efectos adversos gastrointestinales. Los probióticos reducirían el riesgo de ITU recurrente porque mantiene un $\mathrm{pH}$ bajo, producen citoquinas antiinflamatorias y peróxido de hidrógeno como microbicida. Aún así no puede demostrarse un beneficio significativo con el uso de probióticos dado que los estudios que existen no demuestran evidencia suficiente.

Palabras clave: infección urinaria; cranberries; probióticos.

Revista de la Sociedad Argentina de Diabetes 2019; Vol. 53 (70-78)

\begin{abstract}
In several in vitro studies it was observed that the cranberries juice and cocktail had inhibitory effects on bacterial adhesion but with no bactericidal power; therefore, its use was proposed for urinary infection (UI) prevention. Clinical studies on the efficacy of cranberries juice have been limited and have not shown a decrease in the onset of urinary tract infection (UTI), discouraging prolonged use and occurrene of gastrointestinal adverse effects. Probiotics would reduce the risk of recurrent UTI because they maintain a low pH, produce anti-inflammatory cytokines and hydrogen peroxide as a microbicide. Still, no significant benefit can be demonstrated with the use of probiotics since the existing studies show no enough evidence.
\end{abstract}

Key words: urinary infection; cranberries; probiotics.

Revista de la Sociedad Argentina de Diabetes 2019; Vol. 53 (70-78)
Médica especialista en Nutrición, especializada en Diabetes, Médica del Servicio de Nutrición y Diabetes CEMIC, Ciudad Autónoma de Buenos Aires, Argentina
Contacto de la autora: Estrella Menéndez E-mail: estrellamenendez@yahoo.com.ar Correspondencia: Conesa $19903^{\circ}$ Depto. C (C1428CUD), Ciudad Autónoma de Buenos Aires, Argentina Fecha de trabajo recibido: 25/03/19

Fecha de trabajo aceptado: 03/04/19

Conflictos de interés: la autora declara que no existe conflicto de interés. 


\section{Cranberries}

Varios estudios in vitro observaron que el jugo y cóctel de cranberries tuvieron efectos inhibitorios sobre la adherencia bacteriana a las células del colon y la vejiga. Por lo tanto su uso se propuso en la prevención de la infección del tracto urinario (ITU).

En 1984 Sobota demostró in vitro que el jugo inhibía la adherencia bacteriana pero no tenía poder bactericida'. Otro estudio pionero en 1989 de Sharon et al. examino in vitro el efecto del jugo y el cóctel de cranberries sobre las lectinas de superficie expresadas por la E. coli Ambos inhibieron la adherencia de las fimbrias tipo 1 específicas a manosa y las fimbrias $P$ específicas a $\alpha D$ gal (1-4) o B gal.

Los autores concluyeron que el jugo y el cóctel de cranberries contienen al menos dos inhibidores de la adherencia mediada por lectinas de las bacterias patógenas del epitelio urinario. Los mediadores de este efecto de antiadherencia podrían ser la fructosa que puede interferir con la adherencia de las fimbrias tipo 1 de la $E$ coli. y las protoantocianinas que pueden inhibir la adherencia de las fimbrias $P$ especificas de E. coll ${ }^{2}$.

A pesar de estos hallazgos in vitro, los estudios clínicos que demuestran la eficacia del jugo de cranberries han sido limitados y determinaron resultados mixtos. Una revisión Cochrane de metaanálisis ${ }^{3}$ para evaluar la efectividad de los cranberries en la prevención de la ITU se publicó en 1998 y actualizó en 2004, 2008 y 2012.

En la actualización del año 2008 se incluyeron 10 estudios y otros 14 se añadieron en la última. Trece estudios $(n=2380)$ evaluaron el jugo/concentrado de arándanos, nueve estudios $(n=1032)$ evaluaron cápsulas o comprimidos, un estudio comparó entre jugo y comprimidos, y otro entre cápsulas y comprimidos. Se concluyó que los productos de cranberries no reducen significativamente la aparición de ITU sintomática en mujeres con infecciones recurrentes (RR 0.86, 95\% Cl 0,71 a 1,04). También se determinó que el consumo a largo plazo de jugo de cranberries estaría desaconsejado.

Comparados con placebo, agua o sin tratamiento los productos con cranberries no reducían la aparición de ITU asintomática en general ni en ninguno de los subgrupos:

- Ancianos (RR $0.7595 \% \mathrm{Cl} 0,39-1,44)$.

- Niños (RR 0.48 95\% Cl 0,19-1,22).

- Embarazadas (RR 1.04 95\% Cl 0,97-1,17).

- Pacientes con cáncer (RR 1.15 95\% Cl 0,75-1,77).
- Pacientes con vejiga neurogénica (RR 0.95 $95 \% \mathrm{Cl} 0,75-1,20)$.

Hubo diferencias significativas entre los efectos adversos gastrointestinales al comparar los productos con cranberries con agua o placebo, y los efectos adversos fueron mayores con los jugos (RR $0.83,95 \% \mathrm{Cl} 0,31.2,27)$

\section{Probióticos}

El uso de probióticos es un nuevo método pensado para reducir el riesgo de ITU recurrente porque puede mantener un $\mathrm{pH}$ bajo, producir citoquinas antiinflamatorias en las células epiteliales y producir peróxido de hidrógeno que el microbicida para E. coli y otras bacterias patógenas. Además los probióticos no producen resistencia a los antibióticos y ofrecen otros beneficios a la salud como la recolonización vaginal con lactobacilos 4 .

A pesar de estas expectativas, en una revisión de nueve estudios ( $n=735$ ) controlados randomizados $^{5}$, cuatro estudios compararon probióticos con placebo, dos probióticos solamente, otros dos compararon probióticos con antibióticos en pacientes con ITU, y un estudio comparó probióticos con placebo en mujeres sanas. Todos los estudios buscaban diferencias en las tasas de ITU recurrente. La mayoría de los estudios tenía muestras pequeñas y reportó detalles metodológicos insuficientes para permitir una evaluación adecuada. No se encontró una reducción significativa en el riesgo de ITU recurrente entre pacientes tratados con probióticos vs placebo (seis estudios $n=352$ : RR $0,82,95 \% \mathrm{Cl} 0.60$ a 1,12) con intervalos de confianza anchos y baja heterogeneidad estadística. Tampoco se encontró reducción significativa en el riesgo de ITU recurrente entre pacientes tratados con probióticos vs antibióticos (un estudio, $n=223$, RR 1,12 95\% 0,95 a 1,33). Los autores concluyeron que no puede demostrarse un beneficio significativo en el uso de probióticos por el momento dado que los estudios eran pequeños y metodológicamente pobres, por lo tanto la evidencia aún es insuficiente.

\section{BIBLIOGRAFÍA}

1. Sobota $A E$. Inhibition of bacterial adherence by cranberry juice: potential use for the treatment of urinary tract infections. J Urol 1984; 131(5): 1013-16.

2. Zafriti D, Ofek I, Adar R, et al. Inhibitory activity of cranberry juice on adherence of type 1 and type $P$ fimbriated $E$ coli to eucaryotic cells. Antimicrobial agents and chemotherapy 1989; 33(1):92-8. 
3. Jepson R, Williams G, Craig J. Cranberries for preventing urinary tract infections Cochrane Database of Systematic Reviews 2012, 10. doi: 10.1002/14651858.CD001321.

4. Gupta V, Nag D, Garg P. Recurrent urinary tract infections in women: How promising is the use of probiotics? Indian J Med Microbiology 2017 ;35(3):347-354.
5. Schwenger EM, Tejani AM, Loewen PS. Probiotics for preventing urinary tract infections in adults and children. Cochrane Database of Systematic Reviews 2015,12 doi: 10.1002/14651858.CD008772.

\section{CONCLUSIONES FINALES}

Las infecciones del tracto urinario son frecuentes en la práctica clínica con una mayor incidencia en personas con DM, potencialmente asociadas al control glucémico. Esto se debe a una serie de efectos a largo plazo en el sistema genitourinario, incluidos factores inmunológicos e inadecuado vaciamiento vesical. Respecto de la glucosuria como favorecedora de las ITUs, existen controversias y con el uso de inhibidores del cotransportador sodio-glucosa es más frecuente la infección micótica genital y menos la infección urinaria.

La bacteriuria asintomática es más común en mujeres con DM que en aquellas sin DM debido a una combinación con factores de riesgo locales. La DM se asocia frecuentemente con las manifestaciones más graves de la ITU y mayor probabilidad de hospitalización para su tratamiento.

El tratamiento de la ITU en pacientes con DM no difiere del tratamiento en las personas sin DM en términos de elección antimicrobiana o duración del tratamiento, además de las características particulares del paciente y los patrones de resistencia local a los uropatógenos. Es responsabilidad de los médicos utilizar los antimicrobianos adecuadamente, en forma prudente y responsable, basados en guías actualizadas. 